\title{
UTILIZATION AND DISSIPATION OF ABSORBED LIGHT ENERGY IN THE EPIPHYTIC CRASSULACEAN ACID METABOLISM BROMELIAD TILLANDSIA IONANTHA
}

\author{
Craig E. Martin, ${ }^{1}$ Arnd Tüffers, Werner B. Herppich, ${ }^{2}$ and Dieter J. von Willert \\ Institut für Ökologie der Pflanzen, Westfälische Wilhelms-Universität, Hindenburgplatz 55, D-48143 Münster, Germany
}

\begin{abstract}
Past studies of the ability of epiphytic Crassulacean acid metabolism bromeliads to acclimate to different light levels yield conflicting findings; some indicate that these plants are similar to shade plants whereas others stress their similarity to sun plants. This study investigates the ability of individuals of Tillandsia ionantha to acclimate to low or high irradiance. Plants were exposed to 100 and $800 \mu \mathrm{mol} \mathrm{m}{ }^{-2} \mathrm{~s}^{-1}$ photosynthetic photon flux density under controlled conditions for $4 \mathrm{wk}$. Individuals exposed to the lower light level exhibited higher chlorophyll concentrations and higher photosynthetic rates at low light relative to plants exposed to high light. Low-light plants also exhibited a greater efficiency in the photochemical utilization of absorbed light energy and a lower ability to dissipate excess energy nonphotochemically, relative to the plants exposed to the higher light level. Photosynthetic rates at high light were similar in both sets of plants, reflecting the higher efficiency of energy conversion in the low-light plants and an apparent saturation of photosynthetic capacity in the high-light plants. The latter may have resulted from high-light-induced damage to the photosynthetic apparatus in addition to an increase in nonphotochemical dissipation of excess light energy. The higher capacity for harmless dissipation of excess light energy in the high-light plants should prove beneficial in plants growing in exposed locations and subject to drought and nutrient stresses. Thus, the results support and expand those of previous studies: T. ionantha can acclimate to both low and high light but does so in different ways. Such flexibility in adjusting the photosynthetic apparatus to varying light levels constitutes a valuable adaptation to growing throughout the canopy of a host tree.
\end{abstract}

Keywords: CAM, epiphyte, fluorescence, sun/shade, Tillandsia, physiology.

\section{Introduction}

In the temperate zone, most plants with Crassulacean acid metabolism (CAM) grow in arid environments and are exposed to high levels of insolation (Winter 1985). Consequently, these plants exhibit morphological and physiological adaptations characteristic of "sun plants" (Nobel 1988; von Willert et al. 1992). Recent studies indicate, however, that, in both CAM and non-CAM plants growing in fully exposed habitats, the interception of sunlight can be excessive and may result in photoinhibition (Demmig-Adams and Adams 1992; Long et al. 1994; Adams and Demmig-Adams 1996). This reduction in photosynthetic activity may result from a diminished capacity of the photosynthetic apparatus (photodamage) or from a diversion of absorbed excitation energy from photosynthesis to nonphotochemical processes (photoprotection).

It is likely that the majority of CAM plants are tropical and subtropical epiphytes (Winter 1985; Winter and Smith 1996). Such plants, mostly orchids but also including bromeliads and ferns, are typically shaded by the host canopy (Benzing 1990). In spite of the high biochemical energy demands associated

\footnotetext{
${ }^{1}$ Author for correspondence and reprints; permanent address: Department of Botany, University of Kansas, Lawrence, Kansas 660452106, U.S.A.; fax 785-864-5321; e-mail ecophys@falcon.cc.ukans.edu.

${ }^{2}$ Current address: Institut für Agrartechnik Bornim e. V., Abteilung Technik im Gartenbau, Max-Eyth-Allee 469, Potsdam, Germany.
}

Manuscript received July 1998; revised manuscript received November 1998. with the CAM photosynthetic pathway, some evidence indicates that these epiphytes are, to some degree, shade adapted or at least are incapable of utilizing full sunlight (Martin et al. 1985, 1986, 1989; Winter et al. 1986; Adams and Osmond 1988; Skillman and Winter 1997). Other studies, however, present contradictory evidence (Benzing and Renfrow 1971; Kluge et al. 1973; Medina 1974, 1987). Thus, it is difficult to draw firm conclusions about the degree of sun and shade adaptations in CAM epiphytes, at least in epiphytic bromeliads that have received the most attention in this regard (review by Martin 1994).

Studies of chlorophyll fluorescence may be useful in understanding the nature of light utilization by CAM plants as has been illustrated in numerous studies, the majority of which indicate that plants growing in more exposed locations often exhibit midday reductions in photosynthetic capacity and enhanced protection from photodamage and that plants in less exposed locations are more efficient in utilizing solar energy in photosynthesis and less efficient at dissipating excess light energy (Adams 1988; Adams et al. 1989; Raveh et al. 1995; Adams and Demmig-Adams 1996; Franco et al. 1996; HaagKerwer et al. 1996). Studies of chlorophyll fluorescence and light utilization have also included at least one species of epiphytic bromeliad, Guzmania monostachia in Trinidad (Maxwell et al. 1992, 1994, 1995). Plants exposed to full sunlight in the dry season had a greater ability to harmlessly dissipate increased inputs of solar energy relative to plants shaded by a full canopy, thus explaining observed reductions in photo- 
synthesis at the highest light levels. The findings indicate that G. monostachia can exhibit characteristics typical of both sun and shade plants.

The majority of previous studies of putative sun/shade adaptations in epiphytic CAM plants have focused on taxa in the genus Tillandsia (Bromeliaceae). As indicated above, results of such studies provide evidence for both sun and shade adaptations in these epiphytes (Martin 1994). Such results were typically based on measurements of photosynthetic gas exchange, not on the manner in which absorbed solar energy is utilized in the leaf. Thus, this study was undertaken to examine the fate of absorbed light energy in the leaves of the epiphytic CAM bromeliad Tillandsia ionantha exposed experimentally to high and low irradiance. This epiphyte was selected because it is typically found throughout the host canopy and is exposed to a range of light levels in situ. Although the responses of this CAM bromeliad to desiccation have been previously examined (Nowak and Martin 1997), its responses to irradiance have received only scant attention (Benzing and Renfrow 1971).

\section{Material and Methods}

\section{Plants and Experimental Treatments}

Individuals of Tillandsia ionantha Planchon (Bromeliaceae) were collected from the trunks of large trees in north-central Mexico and grown in a greenhouse at the University of Kansas for $5 \mathrm{yr}$. Conditions in the greenhouse varied with different seasons but approximated the following values: maximum midday photosynthetic photon flux density (PPFD) of 1000 $\mu \mathrm{mol} \mathrm{m} \mathrm{m}^{-2} \mathrm{~s}^{-1}$, average day/night air temperatures of $27^{\circ} / 20^{\circ} \mathrm{C}$, and approximate day/night relative humidities of $50 \% / 80 \%$. Plants were flown to Germany in the summer of 1994 and maintained under similar conditions in a greenhouse for $4 \mathrm{wk}$ before the experimental treatments. Then, plants were placed in a growth chamber under the following controlled conditions for $4 \mathrm{wk}$ before all measurements: seven plants were exposed to $100 \mu \mathrm{mol} \mathrm{m}^{-2} \mathrm{~s}^{-1}$ for a 10.5 -h photoperiod, day/night air temperatures of $24^{\circ} / 20^{\circ} \mathrm{C}$, and day/night relative humidities of $60 \% / 40 \%$, while eight plants were exposed to $800 \mu \mathrm{mol} \mathrm{m}^{-2}$ $\mathrm{s}^{-1}$ (same photoperiod), day/night air temperatures of $26 \%$ $20^{\circ} \mathrm{C}$, and similar day/night relative humidities. In all cases, plants were watered daily and fertilized weekly with a dilute fertilizer solution containing all macro- and most micronutrients.

At the end of the 4-wk exposure to the two light levels, the measurements described below used attached or detached leaves, and in all cases, only the distal, green portions of leaves oriented perpendicular to the light. Growth rates of $T$. ionantha are extremely slow; thus, these leaves were mature long before the experimental treatments. Following all measurements, each set of plants was switched to the opposite PPFD level, such that the plants previously exposed to low light (designated $L$ in the figures) were exposed to high light for $2 \mathrm{~d}$ before all measurements were repeated (designated $L H$ ), and the plants exposed previously to high light $(H)$ were exposed $2 \mathrm{~d}$ to low light $(H L)$ before repeating all measurements.

\section{Chlorophyll Concentration}

Two leaves were collected from each plant and extracted in $\mathrm{N}, \mathrm{N}$-dimethylformamide (DMF) at room temperature for 10 d. Samples were then heated for several hours at $58^{\circ} \mathrm{C}$. Absorbance of the DMF was measured at 647 and $664.5 \mathrm{~nm}$ using a dual-beam spectrophotometer and pure DMF as a blank. Chlorophyll concentrations were calculated using the equations of Inskeep and Bloom (1985). Leaf chlorophyll concentrations and $\mathrm{a} / \mathrm{b}$ ratios (fig. 1 ) were similar to those found in numerous other species of Tillandsia (see app. IV in Martin 1994).

\section{Photosynthetic $\mathrm{O}_{2}$ Exchange}

At various times throughout the day (no effect of time of day was observed), two leaves were excised from each plant and placed in a Hansatech (Bachofer, Reutlingen, Germany) $\mathrm{O}_{2}$ electrode chamber (Model CB1-D control box). Rates of $\mathrm{O}_{2}$ evolution were measured at $27^{\circ} \mathrm{C}$, a PPFD of 150 or 850 $\mu \mathrm{mol} \mathrm{m}{ }^{-2} \mathrm{~s}^{-1}$, and under high $\mathrm{CO}_{2}$ concentrations (provided by breathing into the chamber interior). A moistened filter paper disk beneath the leaves provided a saturated atmosphere inside the chamber. Following measurements at the two light
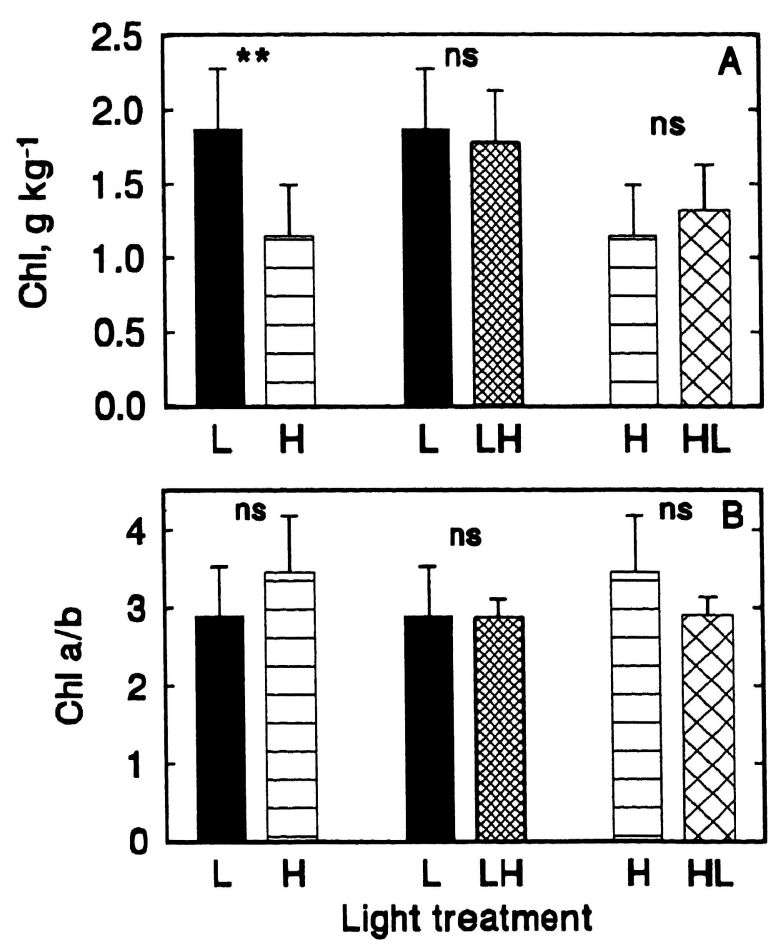

Fig. 1 Mean ( $N=7-8$ plants; SD shown as a projected line from each bar) chlorophyll concentrations $(A)$ and $a / b$ ratios $(B)$ of Tillandsia ionantha after a 4-wk exposure under controlled conditions to $100 \mu \mathrm{mol} \mathrm{m}^{-2} \mathrm{~s}^{-1}$ photosynthetic photon flux density (PPFD; $L$ ) or $800 \mu \mathrm{mol} \mathrm{m}^{-2} \mathrm{~s}^{-1}$ PPFD $(H)$, then after $2 \mathrm{~d}$ at the opposite PPFD level ( $L H=$ low to high; $H L=$ high to low). Each pair of means is significantly different at the $P<0.01$ level $(* *)$ or not significantly different, i.e., $P>0.05$ (ns). 
levels, the leaves were removed and dried at $85^{\circ} \mathrm{C}$ for at least $3 \mathrm{~d}$ before weighing.

\section{Titratable Acidity}

Four (occasionally five) leaves were removed from each plant immediately before lights-out and again before lights-on the next day and frozen at $-30^{\circ} \mathrm{C}$ for at least $1 \mathrm{wk}$. After thawing, the leaves were weighed, ground in deionized water with a mortar and pestle, and titrated to $\mathrm{pH} 7.0$ with $0.01 \mathrm{~N} \mathrm{NaOH}$.

\section{Chlorophyll Fluorescence}

Fluorescence was measured using a PAM-101 Fluorometer with accessories PAM-102 and PAM-103 (H. Walz, Effeltrich, Germany). The measurement head was clamped onto the upper portions of three to four adjacent leaves on each plant. The maximum intrinsic efficiency of energy conversion of Photosystem II $\left(F_{\mathrm{v}} / F_{\mathrm{m}}\right)$ was determined using plants that were darkened for $15 \mathrm{~min}$ beforehand. All other fluorescence parameters, $F_{\mathrm{v}}^{\prime} / F_{\mathrm{m}}^{\prime}$ (the intrinsic efficiency of energy conversion in Photosystem II during exposure to light), $P$ (fraction of absorbed light energy utilized in photosynthesis), and $D$ (fraction of absorbed light energy dissipated nonphotochemically), were measured at either 100 or $780 \mu \mathrm{mol} \mathrm{m}^{-2} \mathrm{~s}^{-1}$ PPFD (FLQ85E cold light source; Olympus Optical Co. Europe GmbH, Hamburg, Germany) inside the measurement head, while the remainder of the plant was exposed to room light. Plants were measured throughout the day; no effects of time of day were obvious. Fluorescence parameters were calculated according to equations in Demmig-Adams et al. (1996). The irradiance of the saturating pulse of white light was $7000 \mu \mathrm{mol} \mathrm{m}^{-2} \mathrm{~s}^{-1}$ (KL1500 cold light source; Schott, Wiesbaden, Germany) applied for $0.7 \mathrm{~s}$.

\section{Statistics}

Because sample sizes were small, it was difficult to adequately test the data for conformity with the assumptions of parametric statistics. Thus, all data were rank transformed, followed by the use of parametric statistics using the ranks of the data (Conover and Iman 1981). The Student's $t$-test (unpaired) was used to compare means for different sets of plants exposed to different light levels, whereas a paired $t$-test was used to compare means for the same plants exposed to different light levels. Statistical theory and application followed Sokal and Rohlf (1981); significant differences were inferred only when $P \leq 0.05$.

\section{Results and Discussion}

The high and low values of PPFD selected in this study constitute realistic estimates of the range of light levels that might be intercepted by individuals of Tillandsia ionantha on a host tree in the field, depending on their location in the canopy. At the collection site in Mexico, most plants of this epiphyte were attached to the central trunk of the host tree, the most shaded location.

Chlorophyll concentrations were substantially lower in plants initially exposed to the high irradiance, relative to those exposed to the lower PPFD (fig. 1A). This finding might reflect a reduced synthesis of antenna complexes at high irradiance or destruction of the chlorophyll as a result of the interception of excess light energy (Demmig-Adams and Adams 1992; Björkman and Demmig-Adams 1994). Higher chlorophyll concentrations are characteristic of shade plants relative to sun plants in a wide variety of studies (Boardman 1977; Björkman 1981). The difference in chlorophyll a/b ratios between plants at the two light levels was not significant (fig. $1 B$ ). Although this finding runs counter to generalizations about the chlorophyll a/b ratios of sun and shade plants (Boardman 1977; Björkman 1981), it is not uncommon. Previous studies of two other epiphytic CAM bromeliads, including a species of Tillandsia, reported similar differences in chlorophyll concentrations and $\mathrm{a} / \mathrm{b}$ ratios in plants growing at high and low irradiance (Martin et al. 1985, 1986; Maxwell et al. 1995). The 2-d treatment at the opposite experimental irradiance, i.e., after low-light plants were moved to high light and vice versa, was apparently too short to effect changes in chlorophyll concentrations (fig. 1A). Rapid changes in chlorophyll contents following changes in exposure, however, were reported in field investigations of the $\mathrm{C}_{3}$-CAM epiphytic bromeliad Guzmania monostachia (Maxwell et al. 1995).

Rates of $\mathrm{O}_{2}$ evolution were measured at or near both experimental light levels for both sets of plants exposed $4 \mathrm{wk}$ to the initial high or low level, as well as after the change in light levels for two more days. When measured at the higher PPFD level, photosynthetic rates of the plants initially exposed to the lower irradiance were the same as those of plants treated at the higher PPFD (fig. 2). On the other hand, photosynthetic rates of the low PPFD-treated plants were higher than those of the high PPFD-treated plants when both were measured at the lower light level. The results indicate that these epiphytes acclimated well to the lower but not the higher light level. Further evidence for this conclusion can be derived from the results of $\mathrm{O}_{2}$ evolution measurements in plants exposed for 2 $\mathrm{d}$ to the opposite light level. Switching the low-light plants to the higher irradiance did not affect the photosynthetic rates at the higher light level; however, rates of $\mathrm{O}_{2}$ evolution at 150 $\mu \mathrm{mol} \mathrm{m} \mathrm{m}^{-2} \mathrm{~s}^{-1}$ were substantially lower after the shift to the higher light level (fig. 2). Likewise, shifting the plants initially exposed to high light to the lower light level did not affect photosynthetic rates measured at $850 \mu \mathrm{mol} \mathrm{m}^{-2} \mathrm{~s}^{-1}$, while those measured at the lower light level increased. Thus, exposure to the higher light level did not result in an increased capacity for photosynthesis at the higher light level relative to that of the low-irradiance plants. Furthermore, treatment at the high light level had a negative effect on these plants, reducing their photosynthetic rate when measured at the lower light level. Past investigations of photosynthesis and acclimation to various light levels in the CAM epiphyte Tillandsia usneoides also report a reduced ability to acclimate to high light levels (see Martin 1994).

Photosynthetic rates of the plants grown and measured at the higher light level were somewhat higher than those of plants grown and measured at the lower light level (fig. 2). This finding was substantiated by the differences between the plants in overnight acid accumulation, a measure of CAM (fig. 3). Although similar trends were observed when the light levels of the two sets of plants were switched, the differences in acid accumulation were not significant (fig. 3). Martin et al. (1986) 


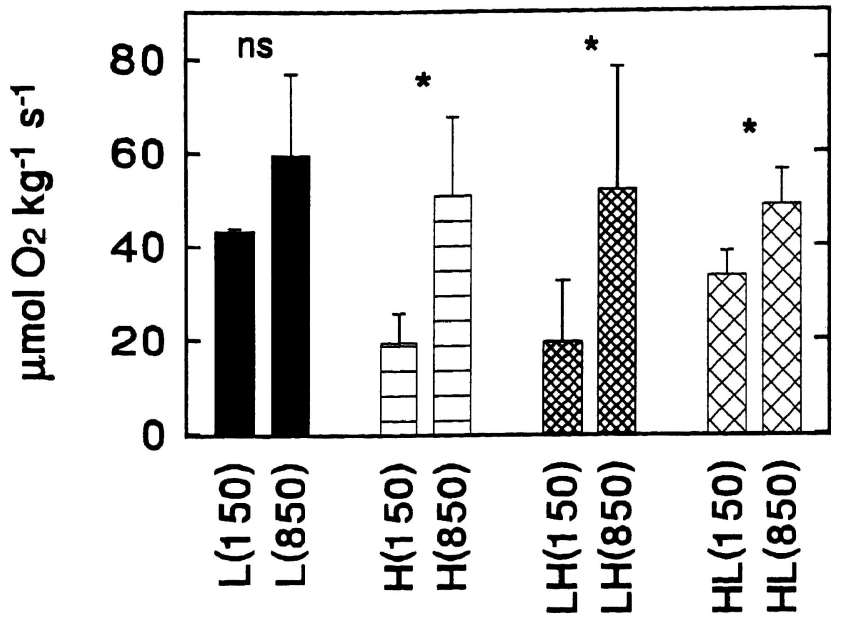

Light treatment

Fig. 2 Mean ( $N=7-8$ plants; SD shown as a projected line from each bar) rates of photosynthetic $\mathrm{O}_{2}$ evolution of Tillandsia ionantha after a 4-wk exposure under controlled conditions to $100 \mu \mathrm{mol} \mathrm{m}^{-2}$ $\mathrm{s}^{-1}$ photosynthetic photon flux density (PPFD; $L$ ) or $800 \mu \mathrm{mol} \mathrm{m} \mathrm{m}^{-2}$ $\mathrm{s}^{-1}$ PPFD $(H)$, then after $2 \mathrm{~d}$ at the opposite PPFD level $(L H=$ low to high; $H L=$ high to low). Rates of $\mathrm{O}_{2}$ evolution were measured at $150 \mu \mathrm{mol} \mathrm{m}{ }^{-2} \mathrm{~s}^{-1}$ PPFD or $850 \mu \mathrm{mol} \mathrm{m}^{-2} \mathrm{~s}^{-1}$ PPFD as indicated in parentheses. Each pair of means is significantly different at the $P<$ 0.05 level $\left({ }^{*}\right)$ or not significantly different, i.e., $P>0.05$ (ns). Results of statistical comparisons not shown in the figure: comparisons of measurements made at $150 \mu \mathrm{mol} \mathrm{m}^{-2} \mathrm{~s}^{-1}$ PPFD: $P<0.001$ for $L-H$, $P>0.05$ for $L-L H$, and $P<0.05$ for $H-H L$; no means of measurements made at $850 \mu \mathrm{mol} \mathrm{m}^{-2} \mathrm{~s}^{-1}$ PPFD were significantly different.

also found increases in the degree of CAM, measured as nocturnal acid accumulation, with increasing irradiance from ca. 50 to $125 \mu \mathrm{mol} \mathrm{m}^{-2} \mathrm{~s}^{-1}$ in the epiphytic congener T. usneoides, although decreases were observed at higher irradiances.

The maximum intrinsic efficiency of energy conversion in Photosystem II, $F_{\mathrm{v}} / F_{\mathrm{m}}$, was higher in plants exposed to the lower PPFD (fig. 4A). The values obtained for these plants were similar to those typically found for most nonstressed plants (Björkman and Demmig 1987). In contrast, the comparatively low values of $F_{\mathrm{v}} / F_{\mathrm{m}}$ found in the plants exposed to high PPFD may indicate damage to the photosynthetic apparatus as a result of an inability to utilize or to dissipate (see below) an excess of light energy (Demmig-Adams and Adams 1992; Björkman and Demmig-Adams 1994; Demmig-Adams et al. 1996). It is also possible that the plants exposed to the higher light level retained some capacity for nonphotochemical quenching in the dark pretreatment used in these experiments (Maxwell et al. 1995; Demmig-Adams et al. 1996). As was the case with the chlorophyll data, the 2-d exposure period was apparently too short to effect any changes in $F_{v} / F_{m}$ after the light regimes of the two groups of plants were switched (fig. $4 A$ ). Similar differences in $F_{v} / F_{m}$, although changes were more rapid, were found in individuals of G. monostachia exposed to different irradiance regimes in Trinidad (Maxwell et al. 1995).

Intrinsic efficiencies of energy conversion in open Photosys- tem II centers, $F_{\mathrm{v}}^{\prime} / F_{\mathrm{m}}^{\prime}$, measured at the same level of PPFD at which plants were experimentally treated for $4 \mathrm{wk}$, were higher in the low PPFD-treated plants relative to those exposed to high PPFD (fig. 4B). Once again, switching the light levels such that plants were exposed to the opposite light level for $2 \mathrm{~d}$ indicated that an exposure period of greater than $2 \mathrm{~d}$ is necessary for acclimatory or inhibitory changes to occur. Lower efficiencies of energy conversion at higher light levels, relative to plants exposed to lower light levels, is a common finding in studies of plants grown at high and low irradiances (Demmig-Adams and Adams 1994, 1996; Herppich et al. 1998). Given these results, it is not surprising that the plants initially exposed to low light utilized a much greater proportion of absorbed energy in photochemistry, relative to plants initially exposed to higher light levels (fig. 5A). Furthermore, a 2-d exposure of the low-light plants to high light resulted in a dramatic reduction in the proportion of energy used in photosynthesis. Also, this proportion increased when the high-light plants were exposed for $2 \mathrm{~d}$ to the low-light regime (fig. 5A).

Corresponding with the above results, the amount of absorbed light energy dissipated via nonphotochemical quenching (NPQ) was lower in the plants initially exposed to low light, relative to the high-light plants (fig. $5 B$ ). The thermal dissipation of absorbed light energy has been correlated with high concentrations of zeaxanthin, a carotenoid implicated as a potential mechanistic basis of NPQ (Demmig-Adams and Adams 1996; Demmig-Adams et al. 1996). Switching the light levels for $2 \mathrm{~d}$ did not significantly change the proportion of absorbed energy dissipated thermally in both sets of plants (fig. 5B). This finding was unexpected, given the changes in proportions of energy utilized in photochemistry in those plants exposed briefly to the opposite light level (fig. 5A). The discrepancy may simply reflect the small sample sizes used in this study. The apparent changes in the means, although not

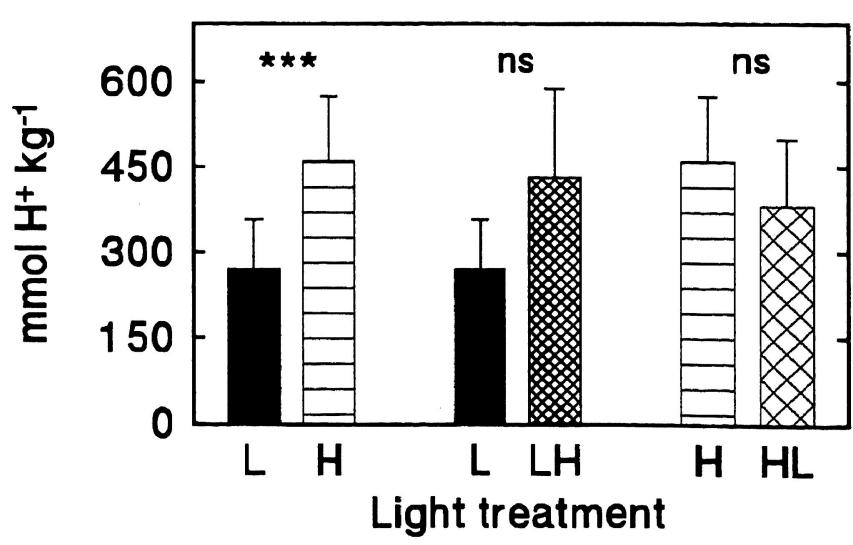

Fig. 3 Mean ( $N=7-8$ plants; SD shown as a projected line from each bar) overnight accumulations of acid in Tillandsia ionantha after a 4-wk exposure under controlled conditions to $100 \mu \mathrm{mol} \mathrm{m} \mathrm{m}^{-2} \mathrm{~s}^{-1}$ photosynthetic photon flux density (PPFD; $L$ ) or $800 \mu \mathrm{mol} \mathrm{m} \mathrm{m}^{-2} \mathrm{~s}^{-1}$ PPFD $(H)$, then after $2 \mathrm{~d}$ at the opposite PPFD level ( $L H=$ low to high; $H L=$ high to low). Each pair of means is significantly different at the $P<0.001$ level $\left({ }^{* * *}\right)$ or not significantly different, i.e., $P>$ 0.05 (ns). 

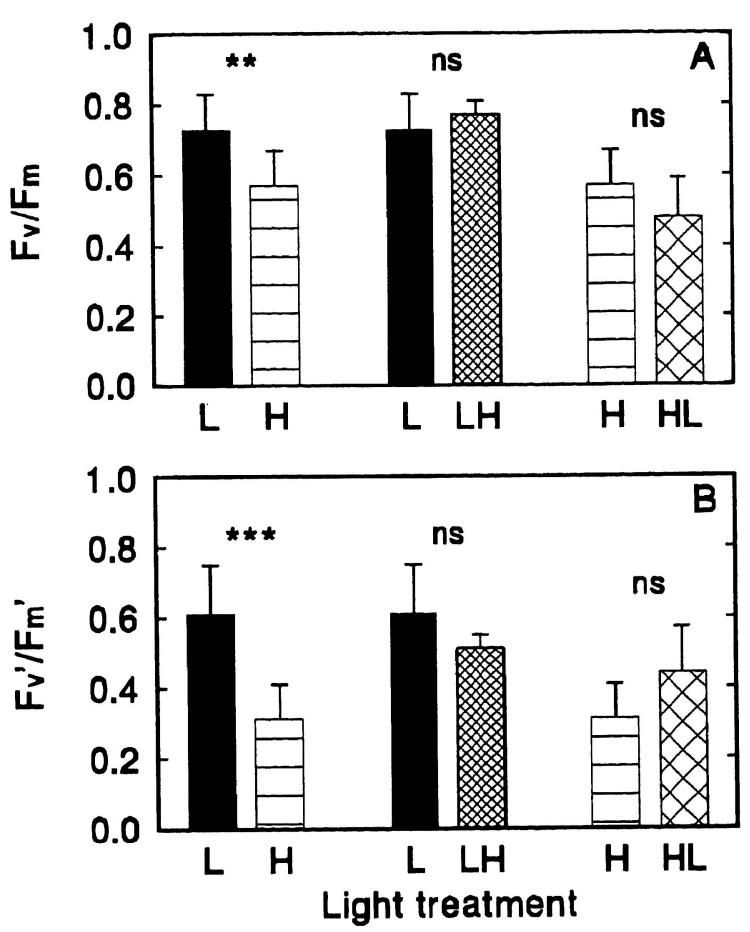

Fig. 4 Mean $(N=7-8$ plants; SD shown as a projected line from each bar) values of the intrinsic efficiency of light energy conversion in Photosystem II in plants of Tillandsia ionantha in the dark ( $A$, $\left.F_{v} / F_{m}\right)$ or in the light $\left(B, F_{v}^{\prime} / F_{m}^{\prime}\right)$ after a 4-wk exposure under controlled conditions to $100 \mu \mathrm{mol} \mathrm{m} \mathrm{m}^{-2} \mathrm{~s}^{-1}$ photosynthetic photon flux density (PPFD; $L$ ) or $800 \mu \mathrm{mol} \mathrm{m}^{-2} \mathrm{~s}^{-1}$ PPFD $(H)$, then after $2 \mathrm{~d}$ at the opposite PPFD level ( $L H=$ low to high; $H L=$ high to low). Each pair of means is significantly different at the $P<0.01$ level $(* *), P<0.001$ level $(* * *)$, or not significantly different, i.e., $P>0.05$ (ns).

statistically significant, were in the expected directions. On the other hand, discrepancies in the absorbed energy budget have been referred to as "excess" energy (for values under the various treatments, see legend, fig. 5); the fate of this energy is unknown (Demmig-Adams et al. 1996).

In most cases, acclimatory changes in photosynthetic and fluorescence parameters were small and not significant $2 \mathrm{~d}$ after the light regimes of the plants were changed. Results of other studies with CAM and non-CAM taxa indicate that changes in these physiological parameters can occur within minutes or hours of altered environmental conditions (Adams et al. 1989; Dau 1994; Maxwell et al. 1995; Haag-Kerwer et al. 1996). The unusually slow response of $T$. ionantha requires further study.

Overall, the results of this study support conclusions of past studies that epiphytic CAM bromeliads can acclimate to both high and low light levels, yet are more efficient in their utilization of lower irradiances. Plants growing at low light have increased chlorophyll concentrations and higher intrinsic efficiencies of light energy utilization, yet a lower capacity for thermally dissipating light energy absorbed in excess of their capacity to utilize it in photosynthesis relative to high-light plants. Plants growing at high light have reduced chlorophyll concentrations, lower intrinsic efficiencies of light energy util- ization, and a higher capacity for thermally dissipating excess light energy.

These findings provide insight into the mechanisms underlying the observed differences in photosynthetic capacity in the two sets of plants exposed to low and high light levels. The higher chlorophyll content, coupled with an increased efficiency of energy utilization in the light reactions, apparently leads to higher rates of photosynthesis measured at low light in the low-light plants, relative to those exposed to high light. In contrast, the finding that both low-light and high-light plants exhibited similar photosynthetic rates at high irradiance indicated that exposure to high irradiance did not result in an increased capacity for photosynthesis at high light. These findings indicate that these CAM epiphytes are better adapted to the shade than exposure to full sunlight. On the other hand, results with $T$. ionantha indicate that acclimation to higher light levels is expressed not as an increased photosynthetic capacity at high light but rather an increased capacity for thermal dissipation of excess energy, which should prove beneficial in avoiding damage due to the absorption of light energy in
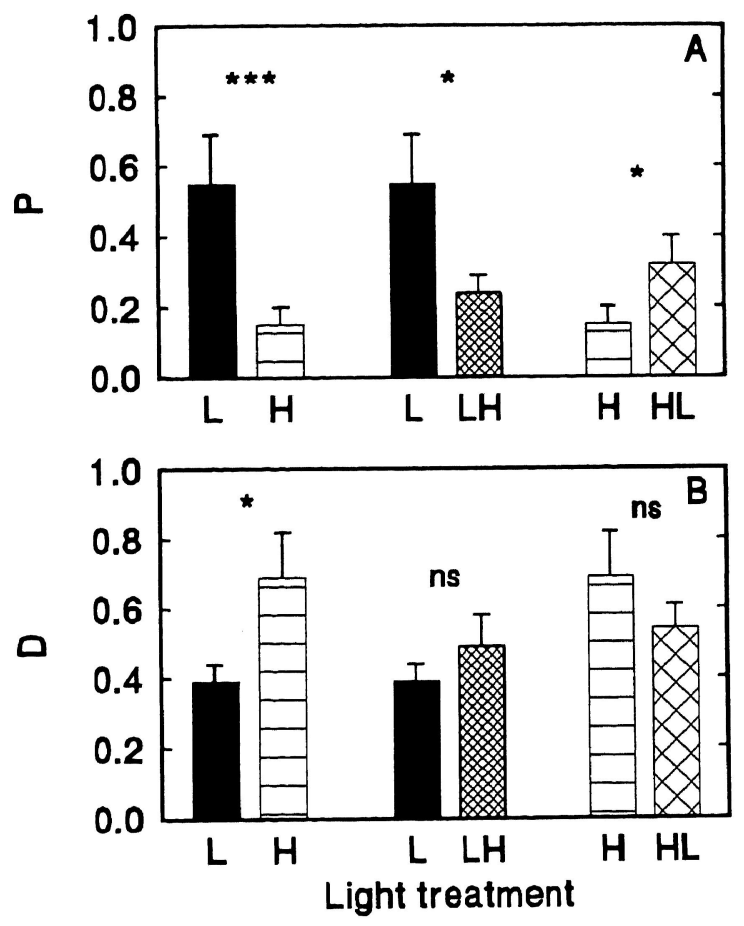

Fig. 5 Mean ( $N=7-8$ plants; SD shown as a projected line from each bar). $A$, Fractions of absorbed light energy utilized in photosynthesis $(P)$. B, Fractions of absorbed light energy dissipated nonphotochemically $(D)$ in Tillandsia ionantha after a 4-wk exposure under controlled conditions to $100 \mu \mathrm{mol} \mathrm{m}^{-2} \mathrm{~s}^{-1}$ photosynthetic photon flux density (PPFD; $L$ ) or $800 \mu \mathrm{mol} \mathrm{m}^{-2} \mathrm{~s}^{-1}$ PPFD $(H)$, then after $2 \mathrm{~d}$ at the opposite PPFD level ( $L H=$ low to high and $H L=$ high to low). Each pair of means is significantly different at the $P<0.05$ level $(")$, $P<0.001$ level $(* * *)$, or not significantly different, i.e., $P>0.05$ (NS). The mean ( $\pm S D ; N=7-8$ ) fraction of energy not used in photosynthesis nor dissipated, i.e., excess energy, for each treatment follows: $L, 0.06 \pm 0.02 ; H, 0.16 \pm 0.08 ; L H, 0.26 \pm 0.06 ; H L, 0.12 \pm 0.16$. 
excess of photosynthetic capacity in exposed habitats. This feature would prove especially useful under exposed conditions when other potential stresses, e.g., drought and low elemental nutrient availability, occurred. In the epiphytic habitat, such combinations of stresses are most likely frequent occurrences (Benzing 1990).

The flexibility in ab:lity to acclimate to different light levels may constitute a common adaptation among these epiphytes, allowing maximal efficiency of light utilization in shaded microenvironments and protection from the potentially damaging effects of excess energy in exposed portions of the host canopy.
Both types of acclimation responses should help to ensure survival and maximal productivity in the unique epiphytic habitat.

\section{Acknowledgments}

This research was completed while Craig E. Martin was funded by a stipend from the Alexander von Humboldt Foundation (Bonn, Germany). The generosity and assistance of this organization were greatly appreciated, as were enlightening discussions of fluorescence theory and methodology with Dr. William W. Adams III.

\section{Literature Cited}

Adams WW III 1988 Photosynthetic acclimation and photoinhibition of terrestrial and epiphytic CAM tissues growing in full sunlight and deep shade. Aust J Plant Physiol 15:123-134.

Adams WW III, B Demmig-Adams 1996 Energy dissipation and the xanthophyll cycle in CAM plants. Pages 97-114 in K Winter, JAC Smith, eds. Crassulacean acid metabolism: biochemistry, ecophysiology and evolution. Springer, Berlin.

Adams WW III, M Diaz, K Winter 1989 Diurnal changes in photochemical efficiency, the reduction state of $Q$, radiationless energy dissipation, and non-photochemical fluorescence quenching in cacti exposed to natural sunlight in northern Venezuela. Oecologia 80: 553-561.

Adams WW III, CB Osmond 1988 Internal $\mathrm{CO}_{2}$ supply during photosynthesis of sun and shade grown CAM plants in relation to photoinhibition. Plant Physiol 86:117-123.

Benzing DH 1990 Vascular epiphytes: general biology and related biota. Cambridge University Press, Cambridge. 354 pp.

Benzing DH, $\&$. Renfrow 1971 The significance of photosynthetic efficiency to habitat preference and phylogeny among Tillandsioid bromeliads. Bot Gaz 132:19-30.

Björkman O 1981 Responses to different quantum flux densities. Pages 57-107 in OL Lange, PS Nobel, CB Osmond, H Ziegler, eds. Physiological plant ecology. Vol 1. Responses to the physical environment. Springer, Berlin.

Björkman O, B Demmig 1987 Photon yield of $\mathrm{O}_{2}$ evolution and chlorophyll fluorescence characteristics at $77 \mathrm{~K}$ among vascular plants of diverse origins. Planta 170:489-504.

Björkman O, B Demmig-Adams 1994 Regulation of photosynthetic light energy capture, conversion, and dissipation in leaves of higher plants. Pages 17-47 in E-D Schulze, MM Caldwell, eds. Ecophysiology of photosynthesis. Springer, Berlin.

Boardman NK 1977 Comparative photosynthesis of sun and shade plants. Annu Rev Plant Physiol 28:355-377.

Conover WJ, RL Iman 1981 Rank transformations as a bridge between parametric and nonparametric statistics. Am Stat 35: 124-129.

Dau H 1994 Short-term adaptation of plants to changing light intensities and its relation to Photosystem II photochemistry and fluorescence emission. J Photochem Photobiol 26B:3-27.

Demmig-Adams B, WW Adams III 1992 Photoprotection and other responses of plants to high light stress. Annu Rev Plant Physiol Plant Mol Biol 43:599-626.

1994 Light stress and photoprotection related to the xanthophyll cycle. Pages 105-126 in CH Foyer, PM Mullineaux, eds. Causes of photooxidative stress and amelioration of defense systems in plants. CRC, Boca Raton, Fla.

1996 Xanthophyll cycle and light stress in nature: uniform response to excess direct sunlight among higher plant species. Planta 198:460-470.

Demmig-Adams B, WW Adams III, DH Barker, BA Logan, DR Bowl- ing, AS Verhoeven 1996 Using chlorophyll fluorescence to assess the fraction of absorbed light allocated to thermal dissipation of excess excitation. Physiol Plant 98:253-264.

Franco AC, A Haag-Kerwer, B Herzog, TEE Grams, E Ball, EA de Mattos, FR Scarano, S Barreto, MA Garcia, A Mantovani, U Lüttge 1996 The effect of light levels on daily patterns of chlorophyll fluorescence and organic acid accumulation in the tropical CAM tree Clusia bilariana. Trees 10:359-365.

Haag-Kerwer A, TEE Grams, E Olivares, E Ball, S Arndt, M Popp, E Medina, U Lüttge 1996 Comparative measurements of gasexchange, acid accumulation and chlorophyll $a$ fluorescence of different species of Clusia showing $\mathrm{C}_{3}$ photosynthesis, or Crassulacean acid metabolism, at the same field site in Venezuela. New Phytol 134:215-226.

Herppich WB, GF Midgley, $M$ Herppich, A Tüffers, $M$ Veste, DJ von Willert 1998 Photosynthetic responses to $\mathrm{CO}_{2}$ concentration and photon fluence rates in the CAM-cycling plant Delosperma tradescantioides Bgr. (Mesembryanthemaceae). New Phytol 138:433440.

Inskeep WP, PR Bloom 1985 Extinction coefficients of chlorophyll a and $b$ in $N, N$-dimethylformamide and $80 \%$ acetone. Plant Physiol 77:483-485.

Kluge M, OL Lange, M v Eichmann, R Schmid 1973 Diurnaler Säurerhythmus bei Tillandsia usneoides: Untersuchungen über den Weg des Kohlenstoffs sowie die Abhängigkeit des $\mathrm{CO}_{2}$-Gaswechsels von Lichtintensität, Temperatur und Wassergehalt der Pflanze. Planta 112:357-372.

Long SP, S Humphries, PG Falkowski 1994 Photoinhibition of photosynthesis in nature. Annu Rev Plant Physiol Plant Mol Biol 45: 633-662.

Martin CE 1994 Physiological ecology of the Bromeliaceae. Bot Rev 60:1-82.

Martin CE, CA Eades, RA Pitner 1986 Effects of irradiance on Crassulacean acid metabolism in the epiphyte Tillandsia usneoides $\mathrm{L}$. (Bromeliaceae). Plant Physiol 80:23-26.

Martin CE, JM McKee, AK Schmitt 1989 Responses of photosynthetic $\mathrm{O}_{2}$ evolution to PPFD in the CAM epiphyte Tillandsia usneoides L. (Bromeliaceae). Photosynth Res 21:145-150.

Martin CE, KW McLeod, CA Eades, AF Pitzer 1985 Morphological and physiological responses to irradiance in the CAM epiphyte Tillandsia usneoides L. (Bromeliaceae). Bot Gaz 146:489-494.

Maxwell C, H Griffiths, AM Borland, MSJ Broadmeadow, CR McDavid 1992 Photoinhibitory responses of the epiphytic bromeliad Guzmania monostachia during the dry season in Trinidad maintain photochemical integrity under adverse conditions. Plant Cell Environ 15:37-47.

Maxwell C, H Griffiths, AM Borland, AJ Young, MSJ Broadmeadow, MC Fordham 1995 Short-term photosynthetic responses of the $\mathrm{C}_{3}$ CAM epiphyte Guzmania monostachia var. monostachia to tropical 
seasonal transitions under field conditions. Aust J Plant Physiol 22: 771-781.

Maxwell C, H Griffiths, AJ Young 1994 Photosynthetic acclimation to light regime and water stress by the $\mathrm{C}_{3}$-CAM epiphyte Guzmania monostachia: gas-exchange characteristics, photochemical efficiency and the xanthophyll cycle. Funct Ecol 8:746-754.

Medina E 1974 Dark $\mathrm{CO}_{2}$ fixation, habitat preference and evolution within the Bromeliaceae. Evolution 28:677-686.

1987 Aspectos ecofisiológicos de plantas CAM en los trópicos. Rev Biol Trop 35:55-70.

Nobel PS 1988 Environmental biology of agaves and cacti. Cambridge University Press, Cambridge. 270 pp.

Nowak EJ, CE Martin 1997 Physiological and anatomical responses to water deficits in the CAM epiphyte Tillandsia ionantha (Bromeliaceae). Int J Plant Sci 158:818-826.

Raveh E, M Gersani, PS Nobel $1995 \mathrm{CO}_{2}$ uptake and fluorescence responses for a shade-tolerant cactus Hylocereus undatus under current and doubled $\mathrm{CO}_{2}$ concentrations. Physiol Plant 93:505511.
Skillman JB, K Winter 1997 High photosynthetic capacity in a shadetolerant Crassulacean acid metabolism plant: implications for sunfleck use, nonphotochemical energy dissipation, and susceptibility to photoinhibition. Plant Physiol 113:441-450.

Sokal RR, FJ Rohlf 1981 Biometry. The principles and practice of statistics in biological research. 2 d ed. W.H. Freeman, New York. $859 \mathrm{pp}$.

von Willert DJ, BM Eller, MJA Werger, E Brinckmann, H-D Ihlenfeldt 1992 Life strategies of succulents in deserts with special reference to the Namib desert. Cambridge University Press, Cambridge. $340 \mathrm{pp}$.

Winter K 1985 Crassulacean acid metabolism. Pages 329-387 in J Barber, NR Baker, eds. Photosynthetic mechanisms and the environment. Elsevier Science, Amsterdam.

Winter K, CB Osmond, KT Hubick 1986 Crassulacean acid metabolism in the shade: studies on an epiphytic fern, Pyrrosia longifolia, and other rainforest species from Australia. Oecologia 68:224-230.

Winter K, JAC Smith 1996 Crassulacean acid metabolism: biochemistry, ecophysiology and evolution. Springer, Berlin. 449 pp. 